\title{
Letramento Acadêmico: Reflexão e Algumas Considerações sobre Cursos de Negócios em Faculdades Privadas Populares ${ }^{1}$
}

\author{
ACADEmiC Literacy: Reflection AND SOME Considerations About \\ Business Courses in Popular Private Colleges
}

Jaeder Fernandes CUNHA*

Resumo: O artigo aborda o processo de "Letramento Acadêmico" em cursos de negócios, área de Ciências Sociais Aplicadas, em específico o curso de Administração de Empresas e afins, ministrados em faculdades privadas populares. Como se sabe o curso é de formação curricular generalista-multidisciplinar; isto significa que sua grade curricular exige aos discentes que adquiram leitura e escrita científicas não apenas de conteúdos de textos, mas de diversos modais, linguagens ou gêneros típicos do nível acadêmico: resumo, resenha, fichamento, relatórios, gráficos, diagramas, fluxogramas, organogramas, tabelas e disposição lógica de números com a aplicação ou não da matemática. O objetivo geral do artigo é propor aos professores uma reflexão sobre o tema visando contribuir para a melhoria do processo ensino-aprendizagem no âmbito do recorte admitido: faculdades privadas de grande escala (ou populares), cursos de negócios e afins dirigidos a alunos advindos em sua maioria da rede pública de educação brasileira. O objetivo secundário é demonstrar diferenças conceituais entre "alfabetização" e "letramento acadêmico", estando este último em contexto específico, isto é, em cursos que, além de serem os mais populares do país,

\footnotetext{
* Mestrado em História da Ciência pela Pontifícia Universidade Católica de São Paulo (2008). Doutorado Direto em História Econômica pela Universidade de São Paulo, USP (2011). Docente e Orientador de Pesquisas da Faculdade Anhanguera de Ribeirão Preto-SP. Bolsista de Pesquisa pela Funadesp - membro do grupo de pesquisa sobre Letramento Acadêmico. Contato: jaederfcunha@ufrj.br.

${ }^{1}$ Com a colaboração de: Cristiane Pimentel Neder, Clinio Jorge de Souza e Luciana Maria Crestani.
} 
são capazes de representar, por seu multidisciplinarismo e difusão, uma preocupação necessária de uma nova agenda de debates em educação.

Palavras-chave: Letramento Acadêmico. Cursos de negócios. Faculdades particulares populares.

\begin{abstract}
The article discusses about the process of the "academic literacy" in business courses, applied social sciences area, specifically the Administration undergraduation course and similars, taught in popular private colleges. As it is known, this is a multidisciplinary-generalist curriculum course in its formation; which means that its curricular schedule requires students to acquire scientifical reading and writing, not only of texts contents, but in many different types of languages or any other typical academic genres, such as summary, review, catalog, reports, graphics, diagrams, flowcharts, org charts, tables and logical arrangement of numbers with or without math application. The main objective of the article is to propose a reflexion to the teachers about this topic, aiming to contribute for a better teaching-learning process, within the admitted approach extent: large-scale private colleges (or popular ones), business courses and related, that are mostly aimed to outcoming students from public brazilian schools. The secondary objective is to demonstrate the conceptual differences between "literacy" and "academic literacy", the latter in a specific context, or in other words, the most popular courses in the country that are able to represent by its multidisciplinarity and difusion, a necessary concern of a new debate agenda on education.
\end{abstract}

Key-words: Academic Literacy. Business courses. Popular private colleges.

\title{
Introdução
}

Este trabalho aborda o conceito de letramento acadêmico e suas linhas limítrofes, estabelecendo distinções entre "alfabetização" e "letramento": esta será a premissa para se compreender o processo de letramento acadêmico, para, a partir de então, elaborar uma reflexão dirigida para cursos de negócios, área de Ciências Sociais Aplicadas - em específico o curso de Administração de Empresas e cursos afins. O contexto social também foi levado em consideração no recorte de nosso objeto de estudo: daremos ênfase aos cursos de negócios mantidos pelas faculdades privadas 
populares. Como se sabe, o curso é de formação generalista-multidisciplinar, o que significa que sua grade curricular exige, por parte dos estudantes, o desenvolvimento de habilidades e competências voltadas para uma diversidade de gêneros típicos da esfera acadêmica: resumo, resenha, fichamento, relatórios, gráficos, diagramas, fluxogramas, organogramas, tabelas e disposição lógica de números com a aplicação ou não da matemática.

O objetivo geral do artigo é propor algumas iniciativas para professores que possam contribuir para a melhoria do processo ensino-aprendizagem no âmbito do recorte aqui admitido: cursos de negócios, faculdades particulares populares, alunos oriundos da rede pública de educação.

Será feita, inicialmente, uma reflexão dos conceitos de alfabetização, letramento e letramento-acadêmico para, em seguida, refletirmos sobre o processo de ensino-aprendizagem nos âmbitos da leitura e da escrita de diversos modais de linguagens típicos da graduação de Administração de Empresas, já que este é um curso que funcionará aqui como uma espécie de amostragem ou representação para toda a área de Ciências Sociais Aplicadas - por contemplar um currículo que absorve disciplinas de Ciências Contábeis, Ciências Econômicas, Ciências Jurídicas, Ciências Sociais, Filosofia, Psicologia, Lógica, Matemática, Engenharias, Tecnologia, entre outras.

É importante salientar que a preocupação deste artigo vai ao encontro dos objetivos da Fundação Nacional de Desenvolvimento do Ensino Superior Particular (FUNADESP), agência de fomento à pesquisa com a missão de desenvolver estudos que estejam dirigidos para melhorias do ensino superior das instituições particulares brasileiras. A FUNADESP é financiadora do projeto de pesquisa "Letramento Acadêmico: da leitura à escrita científica", de grupo de pesquisa multidisciplinar constituído por professores doutores da Anhanguera Educacional ${ }^{2}$.

\section{Justificativa da Escolha do Tema}

Por que ensinar estudantes de nível universitário a ler e a escrever? Não são atribuições dos ensinos básico, fundamental e médio? Por que

${ }^{2}$ Os componentes do grupo são: Prof. Dr. Clinio de Souza (Coordenador), Prof. ${ }^{a}$ Dr. ${ }^{a}$ Cristiane Neder, Prof. ${ }^{a}$ Dr. ${ }^{a}$ Luciana Crestani; Prof. Dr. Jaeder Fernandes Cunha. 
analisar o processo de ensino-aprendizagem que se inicia com a leitura e se estende à escrita científica em cursos específicos de negócios? Nos últimos anos, pesquisadores de países centrais e periféricos vêm demonstrando uma maior preocupação em relação à leitura e à escrita científicas. Os estudantes recém-ingressos na universidade apresentam dificuldades em produzir gêneros típicos do ensino universitário: fichamento, resenha, resumo, gráficos, diagramas, fluxogramas, etc.. Logicamente que tal cenário não é comum em todas as instituições; a diferença reside no grau de excelência de ensino de uma instituição versus instituições de baixa qualidade de ensino considerando que os melhores alunos são selecionados para as melhores universidades, restando aqueles com desempenho ruim ou abaixo de determinado nível instituído para as demais instituições.

No Brasil, este cenário é conhecido: as melhores instituições são, em sua grande maioria, as públicas, e as piores, as particulares - as primeiras atendem geralmente os estratos sociais superiores e, as segundas atendem, sobretudo, os jovens (ou não) de classes menos favorecidas, advindos de famílias de baixo nível de escolaridade (sendo que, na maioria das vezes, são eles os primeiros da família a ingressarem num curso universitário). Obviamente, a educação privada tornou-se uma indústria lucrativa e segmentada: há instituições privadas que atendem somente alunos pertencentes às famílias de alta renda, destacando-se algumas emblemáticas no país, que se tornaram referências em pesquisa e ensino, e há àquelas que atendem um público heterogêneo (diversas classes sociais) - há as pequenas e médias faculdades e há aquelas configuradas em rede de ensino detentoras de grande escala e de gestão profissional (algumas de capital aberto, com emissão de ações em bolsa de valores); exploram um nicho de mercado extremamente grande no Brasil, os alunos advindos das classes de consumo B (-) e $\mathrm{C}^{3}$.

${ }^{3}$ A classificação das classes de consumo é determinada pelo Instituto Brasileiro de Geografia e de Estatística (IBGE): Classe A: famílias com renda igual ou superior a 20 salários mínimos; Classe B: famílias com renda entre 10-20 salários mínimos - a classe B (menos) é um misto entre classes B e C; Classe C: famílias com renda entre 4-10 salários mínimos; Classe D: famílias com renda entre 2-4 salários mínimos; Classe E: famílias com renda até 2 salários mínimos. Há outros indicadores de consumo analisados para esta classificação, tais como: aparelhos domésticos, metragem e quantidade de cômodos da residência da família, entre outros. 
Considerando o retrato social brasileiro, o problema é identificado nas instituições particulares populares de ensino superior. Dentre esses discentes uma boa parcela está matriculada em cursos da área de Ciências Sociais Aplicadas, destacando-se o curso de Administração e afins. Vejamos: o Censo da Educação Superior de 2010, realizado pelo IBGE (Instituto Brasileiro de Geografia e Estatística) mostra que o total de matrículas no país, considerando instituições públicas e privadas, é de 6.379 .299 , das quais 4.736.001 são das instituições particulares, isto é, 74,24\% do total. Cruzando estas informações com um levantamento realizado pela Fundação de Amparo à Pesquisa no Estado de São Paulo ${ }^{4}$ (FAPESP), em 2006, mais de $40 \%$ das matrículas foram realizadas na área de Ciências Sociais Aplicadas a qual denominou de Ciências Sociais, Negócios e Direito. Somente no Estado de São Paulo, 42,5\% de todos os alunos matriculados situam-se nesta área do conhecimento. No Brasil, excetuando o Estado de São Paulo, $41,8 \%$. Esta pesquisa mostra que os cursos mais procurados no Brasil são Administração e Direito, sendo que 30,4\% dos alunos destes cursos estão nas universidades públicas, enquanto $69,6 \%$ deles se encontram em universidades particulares.

Confirmação de nossa hipótese são os resultados dos exames da Ordem dos Advogados do Brasil (OAB), em que a taxa de aprovação frequentemente não atinge $20 \%$ dos egressos dos cursos de Direito. Desde 2010, quando foi instituído o Exame da Ordem Unificado, foram recebidas 628.731 inscrições, das quais 111.738 foram aprovadas, um índice médio de aprovação de $17,7 \%$. O agravante reaparece quando se elabora um ranking de aprovação das seis últimas edições: entre as 20 instituições que mais aprovam, 16 são federais, quatro estaduais e nenhuma é particular ${ }^{5}$.

Situação semelhante, ou até mais grave, teríamos caso houvesse um exame voltado para cursos de negócios, já que neles o currículo é generalista, com forte presença da disciplina de Matemática e afins. Sabe-se que a disciplina de Matemática é a que apresenta maiores dificuldades de aprendizagem para os alunos dos Ensinos Fundamental e Médio. Nas estatísticas da

${ }^{4}$ Disponível em: <http://www.fapesp.br/indicadores/2010/volume1/cap2.pdf >. Acesso em: 15 ago. 2012.

${ }^{5}$ Disponível em: < http://www.oab.org.br/servicos/examedeordem>. Acesso em: 15 ago. 2012. 
Fundação Universitária para o Vestibular (FUVEST), responsável pela elaboração e aplicação do vestibular da Universidade de São Paulo (USP), a média de acertos em questões de matemática na primeira fase dificilmente ultrapassa a mediana de 3 questões num total de 12 , algo em torno de $25 \%$ de aproveitamento.

Já nas estatísticas apresentadas pelo Instituto Nacional de Estudos e Pesquisas Educacionais Anísio Teixeira (INEP), na aplicação do Exame Nacional do Ensino Médio (ENEM), nos últimos seis anos, a maior diferença entre o desempenho dos alunos da rede pública em comparação à rede privada do Ensino Médio está na prova de "Matemática e suas tecnologias". Em 2010, por exemplo, num total de 1.000 pontos disputados, a diferença ficou em 90,54 pontos, ou seja, as escolas de Ensino Médio particulares obtiveram $17,7 \%$ de desempenho superior em relação às escolas públicas. Nas demais provas, as diferenças foram menores: "Ciências Humanas e suas tecnologias", 66,28 pontos (diferença de 12,9\%); "Linguagens, códigos e suas tecnologias (Português)", 65,25 pontos (diferença de 12,6\%); "Ciências da Natureza e suas tecnologias", 61,72 pontos (diferença de 12,3\%); e Redação, 57,56 pontos (diferença de 9,7\%).

Desenhado este quadro, justificamos a escolha do nosso objeto de investigação. A preocupação em refletir sobre o "Letramento Acadêmico" num curso específico da área de Ciências Sociais Aplicadas justifica-se por ser o curso de Administração (ao lado do curso de Direito) aquele que apresenta o maior número de matriculados e formandos do país - estando a grande maioria na rede privada de ensino superior. Por um lado, o curso de Administração é o mais generalista, com baixo nível de reservas de mercado, em que a especialização do aluno graduando - e, na maioria das vezes, já também profissional ou, numa perspectiva mais realista, um trabalhador/assalariado - somente ocorrerá anos mais tarde, após a conclusão do curso de graduação, ao submergir-se às promessas da indústria business school, uma facilitadora de sua efetivação em cursos dispendiosos e de grande apelo comercial denominados de MBA - uma alusão ao Master of Business Administration dos EUA, curso equivalente a um Mestrado Profissional ${ }^{6}$. Por outro lado, o curso de Direito é aquele que concede ao estudante de baixa renda maiores perspectivas, já que, dada à complexidade

${ }^{6}$ No Brasil, o MBA é classificado pelo MEC apenas no nível de especialização lato sensu. 
do sistema jurídico brasileiro, um conhecimento básico de legislação constitui uma vantagem no mercado de trabalho, tanto na área de grandes e pequenas empresas como na administração pública.

Parafraseando as preocupações de Carlino (2006), podemos nos perguntar: por que é necessário ensinar ler e escrever a um aluno universitário? Por acaso, os alunos não deveriam chegar à universidade dominando tais competências e habilidades? Ora, a situação real da educação brasileira e de outros países periféricos não nos permite cruzar os braços. Os alunos oriundos da educação pública, nicho de mercado das instituições de ensino superior privadas populares, não possuem, de fato, em sua grande maioria, um tipo de letramento compatível com aquele requisitado pelo letramento acadêmico. No Índice de Desenvolvimento da Educação Básica (IDEB), medido pelo INEP bienalmente desde o ano de 2005, divulgado em 14 de agosto de 2012, pelo Ministro da Educação Aloízio Mercadante, relativo à leitura de dados coletados em 20117 , o desempenho dos alunos da escola pública fica longe dos ideais 7,0 pontos numa escala de 0 a 10 - considerando que 7,0 pontos é o índice em nível dos países desenvolvidos, em conformidade com a Organização das Nações Unidas (ONU). Vejamos: nos anos iniciais do Ensino Fundamental, a escola pública atingiu 4,7 pontos e a escola privada, 6,5 pontos; nos anos finais do Ensino Fundamental, a escola pública atingiu 3,9 pontos e a escola privada, 6,0 pontos; no Ensino Médio, a escola pública atingiu 3,4 pontos e a rede de escolas privadas, 5,7 pontos.

Portanto, o que pode ser feito para melhorar a situação da maioria dos estudantes universitários brasileiros, ou seja, estudantes de cursos de negócios de faculdades privadas populares? Justifica-se, assim, o recorte de pesquisa aqui admitido. Vale ressaltar que este se deu pelas razões quantitativas apresentadas pelo cenário que descrevemos e pela verificação de poucos estudos dirigidos para esta situação real da educação superior no Brasil.

\section{Letramento, uma Breve Introdução Teórica}

Letramento é palavra e conceito até pouco tempo inéditos. Foram introduzidos no vocabulário da educação e dos estudos em linguagem há

7 Disponível em: <http://ideb.inep.gov.br/resultado/resultado/ resultadoBrasil.seam?cid=123303>. Acesso em: 15 ago. 2012. 
pouco mais de vinte anos (SOARES, 2004). O surgimento do vocábulo pode ser entendido como configuração necessária para nomear comportamentos sociais no ato de aprendizagem e da prática da leitura e da escrita, que extrapolam os procedimentos de decodificação do sistema alfabético e ortográfico, em outras palavras, os procedimentos habituais do processo de alfabetização.

Com a especialização do trabalho, processo inerente ao sistema capitalista, as atividades profissionais foram, progressivamente, se tornando dependentes da linguagem escrita. Alfabetizar, no sentido tradicional, foi se tornando cada vez mais obsoleto. Já os comportamentos e práticas sociais de leitura e escrita foram ficando cada vez mais visíveis e, foi esta visibilidade que promoveu a necessidade de um novo significante no universo educativo e da linguagem. Numa perspectiva histórica, primeiro surgiu o termo "alfabetização funcional", com o objetivo de diferenciar do termo "alfabetizar": como algo que ia além do codificar e decodificar o sistema alfabético. Foi neste contexto histórico que surgiu o termo "letramento" como uma consequência de uma necessidade e não como proposta pró-ativa. Portanto, o termo "letramento" tem sua origem explicada numa tentativa de ampliação do conceito de alfabetização; letramento e alfabetização são conceitos a priori entendidos como distintos, mas nem sempre em nível de processos foram compreendidos em plenitude: muitas das vezes confundidos ou até mesmo tornados um único procedimento educativo da língua escrita.

Em termos de conceito geral, poderiam até se tornar semelhantes; no entanto, em termos pedagógicos, faz-se necessário pontuar suas zonas limítrofes: alfabetização é a aquisição do sistema convencional de escrita enquanto letramento é nomeação que se dá a práticas e comportamentos sociais no uso da leitura e da escrita de maneira eficiente. Segundo Soares (2004), alfabetização e letramento "distinguem-se tanto em relação aos objetos de conhecimento quanto em relação aos processos cognitivos e lingüísticos de aprendizagem e, portanto, também de ensino desses diferentes objetos" (SOARES, 2004, p. 2, grifos nossos). Para esta autora, alfabetização e letramento, apesar de distintos, são interdependentes e indissociáveis. Apenas faz sentido alfabetizar no contexto de práticas sociais de leitura e de escrita e por meio dessas práticas, as quais nomeamos contemporaneamente de letramento; entretanto, este somente pode se desenvolver por meio do processo ensino-aprendizagem do sistema da escrita, que, por sua vez, se dá através da leitura, codificação e decodificação do sistema alfabético. 


\section{Letramento e Alfabetização}

Se alfabetizar está intrinsecamente relacionado ao processo convencional de ensino-aprendizagem da escrita, letramento está relacionado a que conceito geral? Revendo rapidamente os métodos de alfabetização convencionais adotados no Brasil, percebe-se que se classificam em dois princípios: sintético e analítico. No princípio sintético estão os métodos indutivos (método fônico, método silábico): do particular para o geral partem das partes para o todo, ou seja, partem das unidades menores da língua (sílabas, fonemas) para as maiores (palavra, frase, oração, texto). No princípio analítico estão os métodos dedutivos (método da palavração, método da sentenciação, método global): do geral para o particular-partem do todo para as partes, ou seja, partem das unidades maiores da língua para as menores.

O que se pode depreender desta classificação é que todos os métodos, independentemente do princípio a que estão submetidos, possuem naturezas de ensino-aprendizagem semelhantes: ensinar a ler e a escrever pela codificação e decodificação do sistema alfabético e ortográfico da escrita. Em ambos os casos, as sílabas e fonemas são a priori selecionadas para construção de palavras, que também são previamente escolhidas a fim de serem decompostas em sílabas e fonemas; sentenças e textos são a priori construídos ou selecionados com rígido controle léxico e morfossintático, para ser submetido à decomposição posterior em palavras, fonemas e sílabas.

Nos dois casos, nota-se que a aprendizagem da escrita dependeria com exclusividade de estímulos externos previamente selecionados ou construídos; um processo etapista e progressista fazia-se valer considerando todas as idiossincrasias da herança do positivismo no país: decodificação em nível básico do sistema alfabético como pré-requisito de desenvolvimento de habilidades de uso da leitura e da escrita. Talvez isto já explique em parte o problema aqui destacado: com esta perspectiva acumulativa do conhecimento, as crianças, quando não bem preparadas, chegam à idade universitária e se deparam com um ensino superior continuísta daquela realidade escolar, já que agora os seus professores, também formados pelos métodos convencionais de ensino, não oferecerão alternativas, a não ser partir de pressupostos também etapistas estabelecidos como requisitos mínimos de conhecimento para o nível acadêmico. Não está aqui uma explicação de parte do problema? 
Mas, ainda revendo os métodos de alfabetização adotados no Brasil, nos deparamos, nos anos 80, com o construtivismo de Jean Piaget (18961980), muito difundido aqui por Emília Ferreiro, conforme nos mostra Soares (2004). Essa perspectiva psicogenética da aprendizagem da língua escrita permitia explicar e identificar o processo através do qual o aprendiz constrói o conceito de escrita como representação dos sons da fala por signos. A criança ou o adulto aprendiz se torna alfabético através da interação intensa e diversificada com práticas e materiais reais de leitura e de escrita. O construtivismo, como uma teoria psicológica e não pedagógica, evidenciou os processos espontâneos de compreensão da escrita pela criança, mas, posteriormente, sofreu duras críticas por não oferecer metodologias de ensino compatíveis. Se, por um lado, condenou os métodos que enfatizavam o ensino direto e explícito do sistema de escrita, por outro falhou por não ser sistemático em sua operacionalidade pelos educadores. Diante desta ausência, professores foram levados a acreditar que as relações entre a fala e a escrita seriam construídas pelo aprendiz de forma incidental e assistemática, como decorrência natural da interação de numerosas práticas de leitura e escrita durante a vida social do educando (SOARES, 2004). Em outras palavras, seria a sobreposição do letramento sobre a alfabetização convencional.

No entanto, não foi nem um nem o outro caminho que conduziu a realidade educacional brasileira a um bom estágio: obviamente, há outros fatores, como ausência de investimento público e políticas públicas, além de desenvolvimento econômico e social inadequado, os quais juntos subjazem nossa realidade enquanto país periférico caracterizado pela forte desigualdade social. Mas, o fato é que em termos pedagógicos, não avançamos o suficiente para enfrentar a crise atual da educação brasileira, conforme afirma Soares (2004). No caso do ensino superior privado popular, que, ao se expandir, impulsionado pelo capital, se deparou com uma realidade econômico-social de estudantes vítimas de um processo massivo e ineficiente nos níveis escolares de base. O que se pergunta é: o que fazer diante desta realidade? Estendamos esta reflexão para a esfera universitária, a fim de tentarmos compreender o que pode ser construído como premissas orientadoras aos professores atuantes desta realidade. 


\section{Letramento e Letramento Acadêmico}

Antes de tudo, indaga-se: o que é letramento acadêmico? De forma direta, podemos afirmar que é um dos tipos de letramento. De acordo com Fischer (2008), o letramento acadêmico é a "fluência em formas particulares de pensar, ser, fazer, ler e escrever, muitas das quais são peculiares a um contexto social" (FISCHER, 2008, p. 180). O letramento acadêmico é também, como no letramento nos níveis escolares de base, um processo de desenvolvimento de práticas e comportamentos sociais que interagem continuamente com a escrita, porém se dá para fins específicos daquele domínio social sem desconsiderar a história de vida do aluno universitário: mesmo quando oriundo de estratos sociais menos privilegiados, o estudante não pode ser concebido na esfera universitária como um aluno iletrado. $\mathrm{Na}$ universidade, mesmo nesta que reúne as massas populares, a relação comunitária - professores, alunos e funcionários - é tipificada por letrados. O que se deve saber é que tipo de letramento esse aluno formado nos bancos das escolas públicas brasileiras recebeu ao longo de seu percurso educativo.

Cada indivíduo ou grupo social possui algum tipo de conhecimento sobre a escrita bem como de seu uso em práticas sociais. Assim sendo, os alunos que ingressam na Universidade, acima de tudo são sujeitos e, além disto, são sujeitos letrados que trazem consigo concepções de leitura e escrita construídas numa vida submetida a um contexto social. Porém, apesar de letrados, não conseguem apresentar bom desempenho na universidade ou, quando conseguem tal performance, inesperada para muitos, esta é justificada pela máxima de que "o professor finge que ensina, o aluno finge que aprende, e todos são felizes". Em outros dizeres, trabalha-se com conteúdos rasos e avaliações desonestas. Pergunta-se: ora, então, qual o real problema desse aluno "letrado"?

A resposta talvez esteja nos modelos básicos de letramento apresentados por Street (1984). São eles: o letramento autônomo e o letramento ideológico. No primeiro modelo, pressupõe-se que a escrita se desenvolve de forma independente dos fatores sociais que circundam o sujeito, é a capacidade de ler e escrever tecnicamente, de forma fria e imparcial, um modelo endógeno de desenvolvimento, que se desenvolve em si, por si e para si, sem vinculação com fatores exteriores. É a capacidade de ler e escrever, em que ler significa ser capaz de decodificar as palavras e escrever 
ser capaz de codificar a língua em representação visual (GEE, 1996). Naturalmente, nota-se que os alunos oriundos da escola pública brasileira, e que hoje se sentam nos bancos das faculdades particulares de massas, receberam estes modelo de letramento, em que o ler resume-se no estou vendo e o escrever no estou copiando.

No segundo modelo, o letramento é concebido como uma prática social e não como uma habilidade neutra ou uma técnica desenvolvida por repetições esvaziadas de sentido social crítico. Neste modelo, o letramento do aprendiz está vinculado ao seu contexto social e cultural - ou como quer Norbert Elias (1994), sócio-cultural. A relação ensino aprendizagem se dá através de significados atribuídos ao contexto sociocultural que circuncida os atores sujeitos da relação. Para Terzi (2006), a opção pelo letramento ideológico exige "não apenas ensinar a tecnologia da escrita, ou seja, promover a alfabetização, mas, simultaneamente, oferecer-lhes a oportunidade de entender as situações sociais de interação que têm o texto escrito como parte constitutiva" (TERZI, 2006, p. 5). Em suma, a autora quer dizer que é necessário usar o ensino em situações cotidianas, tornando o aluno um cidadão crítico - além desta conquista, a criticidade do sujeito promove os estímulos cognitivos; o educador atua como um facilitador da aprendizagem.

Porém, a realidade dos alunos oriundos das escolas públicas corresponde ao primeiro modelo: apesar de letrados (ou alfabetizados) reconhecem práticas sociais cotidianas, como função de revistas, jornais, bilhetes, cheques, cartões bancários, e-mails, páginas de redes sociais, internet, jogos, etc. -, não receberam uma concepção de letramento compatível ou suficiente para as práticas letradas do domínio acadêmico. Para Machado, Louzada e Abreu-Tardelli (2004), esses alunos, de repente, se percebem num novo contexto, em que são submetidos a obrigações de leitura e de produção de textos que não lhes foram ensinados nos anos escolares; o letramento que receberam ao longo da vida não considera a escrita como prática social, na verdade apenas foram alfabetizados e, muito das vezes, com falhas funcionais graves, como erros ortográficos simples.

Portanto, o que fazer com tal realidade? Trabalhar com o letramento acadêmico é nossa proposta. O letramento acadêmico, enquanto uma das modalidades de letramento, encaixa-se no modelo ideológico apresentado por Street (1984), ou no modelo expresso de Soares (2004). No entanto, o contexto é distinto da realidade escolar; o domínio acadêmico é próprio de sua história, logo, não é caminho salutar querer inverter a ordem institucional 
ou alterar profundamente o ambiente acadêmico colocando-o à mercê dos estudantes em suas realidades vividas. $O$ estudante está adentrando um contexto de domínio próprio, portanto, é ele quem deve se adaptar, mas isto não significa que não deva haver facilitadores no processo de aprendizagem de um novo discurso: o Discurso acadêmico. Quando a tenra criança deixa sua casa e ingressa nos anos iniciais do Ensino Infantil, se depara com um contexto de socialização profundamente distinto de sua realidade doméstica; fazer parte daquele novo ambiente é fundamental para o seu desenvolvimento. Carlino (2006) nos diz que estudantes e professores habitam mundos culturalmente distintos. Os códigos que os professores manejam são diferentes dos códigos dos alunos, bem como são os modos de proceder com o conhecimento, de ler e escrever. As palavras e os modos de ser são em si um produto de toda uma história de socialização do professor com sua disciplina (CARLINO, 2006, p. 161); isto não pode ser alterado. Mas, algo deve ser feito e nos parece que a solução é a interação e a articulação de várias metodologias de ensino.

\section{Interação e Articulação de Modelos de Ensino}

O ensino-aprendizagem de conteúdos multidisciplinares - característica base dos cursos de negócios, área de Ciências Sociais Aplicadas -, contemporaneamente, é objeto de estudo não somente dos pesquisadores da área de Educação como também de diversas disciplinas. Os raros departamentos de Pós-graduação no Brasil de História da Ciência é um exemplo bem sucedido de pesquisa multidisciplinar dirigida para o ensinoaprendizagem de diversas ciências e disciplinas. Um exemplo interessante de se analisar para a compreensão de nosso objeto é a aprendizagem da língua escrita - objeto de pesquisa de várias ciências -, sendo que cada uma delas enfatiza uma perspectiva: a fônica, que aborda a consciência fonológica, na qual a criança toma consciência da fala como um sistema de sons e transfere tal compreensão para o sistema de escrita, como um molde de representação gráfica desses fonemas, logo fonema-grafemas estabelecem-se como uma relação sonora da fala e gráfica da escrita; a perspectiva da leitura fluente, que exige a compreensão plena das construções frasais; a perspectiva da leitura compreensiva, que admite um vocabulário mais vigoroso quanto habilidades de interpretação, julgamento e inferência; a perspectiva da identificação e utilização das funções da língua escrita dos diversos tipos e 
gêneros textuais; entre outras. Tais perspectivas de um único objeto - a escrita - estão fundamentadas em teorias de aprendizagem da área de Educação e Psicologia e, em princípios da Linguística em diálogo com as demais Ciências Sociais: princípios fonéticos e fonológicos, linguísticos, psicolinguísticos, sociolinguísticos, teorias do discurso, teorias da leitura, etc.. Considerando que cada uma dessas perspectivas para funcionar adota metodologias de ensino diferentes, temos que o diálogo intraperspectivas encontre dificuldades. E este não é o melhor caminho: para Soares (2004), ao tratar do ensino-aprendizagem da língua escrita, a saída está na interação e na articulação de perspectivas de ensino, metodologias diversas:

[...] privilegiar uma ou algumas facetas, subestimando ou ignorando outras, é um equívoco, um descaminho no ensino e aprendizagem da língua escrita, mesmo em sua etapa inicial - talvez por isso temos sempre fracassado nesse ensino e aprendizagem; o caminho para esse ensino e aprendizagem é a articulação de conhecimentos e metodologias fundamentos em diferentes ciências, e sua tradução em uma prática docente que integre várias facetas [...] (SOARES, 2004, p. 4).

Tomando como base para nosso caso, aqui, o ensino de multidisciplinas em cursos de negócios em faculdades populares, onde o aluno recebeu durante o seu percurso escolar um letramento autônomo, conforme Street (1984), temos que a saída está em adotar, em sala de aula, linguagens, abordagens e metodologias de ensino da escrita diversificadas e integradas entre si, e inter-relacionadas aos contextos sociais de vivência desses alunos.

Lea e Street (1998) demonstram três modelos principais de escrita no âmbito universitário: o estudo das habilidades, socialização acadêmica e letramento acadêmico. O primeiro, o estudo das habilidades, compreende o letramento como habilidades cognitivas do indivíduo necessárias para que ele se adapte à realidade acadêmica; portanto, desconsidera a trajetória anterior de letramento do aluno e transfere a ele a incumbência de desenvolver competências metacognitivas de leitura e de escrita, a fim de adaptar-se à realidade universitária. Já o modelo de socialização acadêmica responsabiliza o professor por introduzir os alunos na cultura acadêmica: o vocabulário, o raciocínio, a interpretação e práticas de leitura e escrita das diversas disciplinas 
universitárias; este modelo adota como premissa que os gêneros discursivos acadêmicos se aproximam da homogeneidade, logo, uma vez que o aluno ingressante se sociabilize com tais gêneros, estará habilitado para realizar as práticas letradas que permeiam a cultura acadêmica. Para Zamel (2003 apud RAMIRES, 2007, p. 67), este modelo reforça a ideia de que a instância acadêmica "é monolítica, imutável e suas entidades facilmente identificáveis". E, por fim, o modelo de letramento acadêmico compartilhado pelos autores Street (1984), Barton (1994), Barton e Hamilton (1998) e Gee (1996) compreende que a esfera acadêmica é constituída de múltiplos letramentos e que esses são, no conjunto, práticas sociais; esse modelo inclui a biografia dos alunos em seus contextos valorizando a identidade constituída, possibilitando, assim, uma nova aculturação num novo contexto, facilitando-lhe a adesão a um novo discurso: o Discurso acadêmico.

Entretanto, ratificando a direção que aqui defendemos, vale reforçar que a saída não está na preponderância ou exclusão de um desses modelos, mas na interação, articulação e complementação entre eles: todos esses modelos contemplados auxiliam mais o processo ensino-aprendizagem de novas linguagens sociais e gêneros discursivos do que um modelo só, isolado - a opção por um dos dois primeiros modelos pode legitimar a rotulação de "aluno iletrado", mas complementados pelo terceiro modelo, o de letramento acadêmico, os dois primeiros passam a ser úteis e indispensáveis. E isto está de acordo com o que Soares (2004) afirma ao refletir sobre outra questão, mas de mesma natureza: a realidade da educação brasileira dos anos iniciais na dualidade alfabetização versus letramento, no sentido de mistura, ou de interação e articulação de modelos como o caminho a seguir:

[...] os dois processos - alfabetização e letramento - são, no estado atual do conhecimento sobre a aprendizagem da língua escrita, indissociáveis, simultâneos e interdependentes: a criança alfabetiza-se, isto é, constrói seu conhecimento do sistema alfabético e ortográfico da língua escrita, em situação de letramento, isto é, no contexto de e por meio de interação com material escrito real, e não artificialmente construído, e de sua participação em práticas sociais de leitura e de escrita; por outro lado, a criança desenvolve habilidades e comportamentos de uso competente da língua escrita nas pàaticas sociais que a envolvem no contexto do, por meio do e, em dependência do processo de aquisição do sistema alfabético e 
ortográfico da escrita. Este alfabetizar letrando ou letrar alfabetizando pela integração e articulação das várias facetas do processo de aprendizagem inicial da língua escrita, é, sem dúvida, o caminho para a superação dos problemas que vimos enfrentando nesta etapa da escolarização. (SOARES, 2004, p. 4).

\section{Algumas Considerações sobre Ensino-Aprendizagem nos Cursos de Negócios}

Esses alunos, receptores de uma diversidade de disciplinas e tipos de saberes distintos são obrigados a conviver com disciplinas com as quais ainda não desenvolveram o mínimo de intimidade. A crença de que este aluno é iletrado e/ou despreparado para aprender na esfera acadêmica pode conduzir instituições de ensino a práticas equivocadas, que exigem dos alunos reprodução das convenções discursivas daquele âmbito. $\mathrm{O}$ que propomos é substancialmente o oposto: propomos valorizar os significados produzidos pelos alunos, em suas práticas acadêmicas, a partir dos significantes apresentados pelos educadores, na tentativa continuada de resgatar as experiências do cotidiano desse aluno como interdiscurso e linguagem figurada na fala e no demonstrar - que, em metodologia científica, é distinto de mostrar - dos saberes dos professores já sociabilizados de longa data com suas disciplinas. Assim sendo, os alunos terão uma via de passagem de reprodutores para produtores de seus próprios discursos.

Na prática, propomos que o aluno tenha "experiências ideais" - no sentido dela ocorrer em nível das ideias, como nos disse o físico Mario Schenberg (gedanken experiment) ao retratar sobretudo as experiências mentais de Albert Einstein - no aprendizado de multidisciplinas. Na matemática financeira, por exemplo: se o ensino do cálculo de juros simples, juros compostos, taxas nominais e taxas efetivas, exemplificando, for relacionado com práticas do cotidiano dos alunos, relacionando a técnica às lembranças costumeiras da prática já praticadas consciente e inconscientemente por eles, as técnicas de cálculo deixarão de ser meras técnicas apreendidas pela repetição e se tornarão naturalmente em compreensão sistêmica de práticas financeiras deles próprios em suas atuações rotineiras e necessárias do dia a dia em bancos, lojas e estabelecimentos comerciais. Se nada for feito, temos que antes e durante a iniciação das primeiras lições dessa disciplina o aluno se imaginará sabedor do objeto e/ou dos objetivos da disciplina - 
impressionado pelo próprio título insígnia -, mas, no desenrolar do conteúdo, é possível que esse mesmo estudante venha a se defrontar com dificuldades de compreender até mesmo a função social do curso. Ao tratar dos cálculos para se obter o valor da prestação mensal a partir do ensino de modelos de amortização de dívidas, por exemplo, é sugerível que o professor relacione o Sistema de Amortização Constante (SAC) a uma situação real de compra de um apartamento por um dos alunos da classe. Ou que exemplifique diferenças de taxa nominal e taxa efetiva de juros através de um anúncio midiático de uma grande rede de lojas de departamentos. Ou demonstre o Desconto Bancário de Duplicatas a partir da perspectiva de uma aluna funcionária ou proprietária de uma pequena loja de roupas, onde a alavancagem de capital de giro se faz necessária.

No ensino de um fluxograma, na disciplina de Organização, Sistemas e Métodos (OSM), por exemplo, a explicação da análise pode se dar por uma linguagem sistêmica conhecida: a linguagem de um jogo virtual ou mesmo pela explicação de funções sequenciais de funcionamento comum de uma família com cinco pessoas residindo em uma mesma casa. Podemos imaginar o ensino de processos de recrutamento e seleção, da área de Recursos Humanos, a partir da perspectiva de jogos coletivos, como o futebol, nos quais os melhores jogadores são aqueles que se enquadram nas funções com maior aderência às suas habilidades e competências, bem como aqueles que possuem o melhor do espírito de equipe. Aproveitando o exemplo, podemos falar de "autoridade" versus "liderança" trabalhando as crenças, a cultura e a composição dos atletas de um time vencedor do campeonato em andamento ou daquele que acabou de se conhecer o campeão. Bem como podemos analisar os estilos de gestão a partir da análise de diversas lideranças, até mesmo utilizando, como linguagem figurativa, técnicos de futebol conhecidos em seus estilos de comando.

Podemos também ensinar Economia Empresarial, ao tratar de microeconomia aplicada, bem como os fatores (ou, segundo tese de Michael Porter (1986), "forças") no funcionamento de determinada indústria, tais como concorrentes, tecnologia, entrantes novos, barreiras de entrada, barreiras de saída, governo, etc.. Exemplo interessante também é o que este autor denominou de "Estratégias Genéricas" -, utilizando-nos de exemplos muito conhecidos, como: fusão de grandes redes de lojas, incorporação de bancos populares, estratégias de marcas com altos índices de lembrança pelo consumidor, etc.. O importante é fazer com que o aluno aprenda 
trabalhando sua imaginação e raciocínio para elaborar, pelas vias do pensamento, o seu próprio discurso em consonância ao discurso legitimado no âmbito acadêmico.

Numa aula de Análise de Balanços Contábeis, ou de Auditoria, ou de Controladoria, o ideal é que o professor consiga trabalhar com empresas reais que publicam seus relatórios contábeis por força de lei - considerando que as empresas de capital aberto ou Sociedades Anônimas (SA) são regidas pela Lei $n^{\circ}$ 6404/76 (BRASIL, 1976), logo, obrigadas a publicar periodicamente seus resultados para os investidores ou mercado. Que o professor possa ensinar o aluno a desenvolver uma lógica de compreensão simples, mas que seja suficiente para lhe dar o ponto de partida de desenvolvimento a ponto de, com o tempo, esse aluno aprendiz poder identificar fraudes e desvios financeiros. Considerando que muitos desses alunos desenvolvem lógica de alta complexidade em jogos virtuais simples instalados em aparelhos de celular e congêneres, há de se ter meios de motivá-los a buscar nos estudos de análise contábil o desenvolvimento de suas faculdades cognitivas para tal finalidade. O Laboratório de Informática associado a lições simples de lógica e aos exemplos reais do cotidiano podem ser grandes aliados do professor dessa disciplina.

No ensino de Introdução à Economia podemos imaginar que uma exposição de diálogo interdisciplinar pelo professor pode facilitar substancialmente o aprendizado. Embora a Economia tenha seu núcleo de análise e seu objeto bem definidos, sabe-se que ao se desenvolver enquanto Economia Política no contexto histórico da Ciência Moderna estabeleceu relações salutares com as disciplinas de Física e Biologia durante os séculos XVIII e XIX. Portanto, se de um lado as leis da Economia se comportam como as leis da Física - daí advêm termos como dinâmica, estática, estoques, aceleração, velocidade, forças, etc., - de outro lado a Economia se comporta como um organismo - de onde advêm termos como órgãos, fluxos, funções e circulação. Quanto a este último, por exemplo, o historiador econômico Fernand Braudel (1996) nos admoesta que o termo somente surgiu na Economia após a publicação da Teoria da Circulação Sanguínea, pelo médico britânico William Harvey $(1578-1657)^{8}$. Independentemente da disciplina, o

8 "Um tratado anatômico sobre o movimento do coração e do sangue nos animais", publicado em 1628 é considerada a obra mais importante de toda a história da Fisiologia. 
importante é que, em cursos multidisciplinares, "o interessante", que se dá pela aproximação da disciplina ao cotidiano do aluno, possa ser o ponto atrativo entre o estudante e a "matéria", intermediados pelo educador, um facilitador por missão - ou tradição filosófica de Platão.

Naturalmente, todo este conteúdo multidisciplinar é composto de textos e gêneros diversos típicos destas disciplinas de âmbito acadêmico. Logo, resenha, fichamento, relatórios, gráficos, diagramas, fluxogramas, organogramas, tabelas e disposição lógica de números com a aplicação ou não da matemática são linguagens rotineiras de um estudante de Administração e cursos afins. Com base nas pesquisas de Paula Carlino em seu Escribir, leer y aprender en la universidad (2005), propomos, para conteúdos textuais, a utilização de fichas e guias de leitura. As "fichas de leitura" funcionam como sintetizadores de um processo de aprendizagem. Nelas, o aluno responderá a si mesmo - e após a leitura, naturalmente - questões elementares para uma melhor compreensão do texto: uma compreensão holística, sistêmica, na qual se conhece o todo pelas partes e vice-versa. $\mathrm{Na}$ "guia de leitura", o aluno elaborará um estudo analítico e comparado entre obras estudadas, sejam de mesmo autor ou autores diferentes, sejam da mesma disciplina ou disciplinas distintas em diálogo.

Universidades têm tomado consciência de que se requer um diálogo interdisciplinar entre especialistas no ensino de suas disciplinas bem como no ensino da escrita e da leitura para que as matérias possam transmitir aos seus alunos sua cultura cabal: seus conceitos e seus modos de pensamento organizados em torno de seus escritos. (CARLINO, 2005, p. 111).

Além do ensino-aprendizagem de natureza interdisciplinar, consideramos que seja fulcral "a busca", no sentido de resgate ou de alcance do professor educador pelo aluno. Uma metáfora válida: projetos sociais de músicos e orquestras de música clássica e erudita nas comunidades carentes das grandes cidades. Não são os meninos pobres que vão até a música do Velho Mundo, mas são os concertistas e recitalistas eruditos os que alcançam esses "oprimidos" - referimo-nos aqui à Pedagogia do Oprimido, de Paulo Freire (1983). 


\section{Considerações Finais}

Os fatos do recorte do objeto deste trabalho resumem-se em estudantes oriundos em sua maioria da rede pública brasileira, ingressantes na esfera universitária pelas vias dos cursos mais populares, os cursos de negócios, em instituições particulares de grande escala que se espalham pelo país em formato de redes de ensino com fortes tendências de serem cada vez mais instituições de capital aberto, atendendo às exigências de uma indústria cada vez mais lucrativa, de capital concentrado e de gestão profissional. Esses alunos receberam uma formação com baixo nível de criticidade. De acordo com Street (1984), receberam um letramento autônomo, endógeno, descolado de seus contextos socioculturais.

No entanto, esses alunos são sujeitos letrados, mesmo que apresentem deficiências em correlacionar o letramento recebido no percurso de vida estudantil escolar e o letramento acadêmico. A questão que colocamos é: o que se deve fazer num contexto de sala de aula repleta de alunos (cem alunos em média) letrados originalmente nos bancos da escola pública e que, agora, matricularam-se em cursos de negócios multidisciplinares por natureza?

Ora, em primeiro lugar, consideramos que o professor não pode subestimar a capacidade cognitiva do educando. Por outro lado, deve ser um facilitador, intermediando o aprendiz e a aprendizagem - o aprender e o conhecer, o conteúdo e a compreensão de mundo. Parafraseando o que já é lugar-comum, o professor deve se tornar um educador, um mediador da relação ensino-aprendizagem. Como inspiração, evocamos Paulo Freire (1983, p. 79): "ninguém educa ninguém, como tampouco ninguém se educa a si mesmo: os homens se educam em comunhão, mediatizados pelo mundo". Na perspectiva freiriana, somadas às contribuições dos autores que citamos até aqui, faremos nossas considerações finais.

Vejamos: os nossos alunos (tipificados no recorte deste trabalho) viveram experiências em seus percursos estudantis e cada um deles possui uma visão de mundo construída pelas experiências vividas. Logo, aproveitando-nos de uma contribuição de Ortega y Gasset (1993), o processo de vida como biologia passa a ser vida como biografia.

Sugerimos que a vida vivida no mundo por cada educando seja um contributo fundamental nas ações e falas do educador em sala de aula. Se as condições impostas compreendem educar alunos destituídos do Discurso 
acadêmico - com D maiúsculo -, então nos cabe decodificar a relação ensino-aprendizagem desse tipo de discurso, utilizando-nos das biografias dos aprendizes. Discursos são "maneiras de ser no mundo, ou formas de vida que integram as palavras" (GEE, 1996, p. 127). Se o Discurso aqui é parte de um contexto peculiar, o acadêmico, então, para este autor "Um Discurso é um tipo de kit de identidade que vem completo com [...] instruções de como agir, falar e também escrever, a fim de aceitar um papel social" (GEE, 1996, p. 127). Mas, se os alunos não conseguem acessar, aprender e apreender este Discurso sozinhos, cabe aos professores - atuando como educadores - auxiliá-los nesta construção de criticidade, a fim de torná-los sujeitos e não massas de manobras de uma "educação bancária" que, conforme Freire (1983, p. 57-62), é dirigida exclusivamente para os interesses de uma elite produtivista, detentora do capital e dos meios de produção e, o pior, absolutamente desinteressada na construção de sujeitos no mundo. Somente através de uma educação dialógica, ou como nos ensina Freire (1983, grifo nosso), "a dialogicidade como prática da liberdade", é que deixarão a condição de vendedores para ser detentores de seu trabalho, condição primaz para elevação de indivíduos a sujeitos no mundo.

Segundo Gadotti e Torres (1994, p. 88), "Se educar é conscientizar, a educação é ato essencialmente político. Portanto, ninguém educa sem uma proposta política". O engajamento político dos professores a fim de tornarem-se educadores é fundamental no processo. É necessário que haja interesse do educador em alcançar o educando; buscá-lo em sua condição sociocultural de origem é imprescindível. Para isto, as afirmativas de Street (1984) em relação ao "letramento ideológico" fazem aqui todo o sentido. Ao exercitarmos o aluno a relacionar as perspectivas do signo fonemagrafema à fala e gráfica acadêmicas, poderemos obter numa articulação de facetas a perspectiva de um Discurso acadêmico mais eficiente quanto às habilidades de interpretação, julgamento e inferência - além da identificação e utilização das funções dos tipos e gêneros textuais da esfera universitária, conforme quer Soares (2004). O engajamento do professor constitui interesse pela reflexão do ato de educar e educar-se: "Quem ensina aprende ao ensinar e quem aprende ensina ao aprender” (FREIRE, 1996, p. 25). Nos colocarmos na situação do outro é o ponto de partida legítimo para educar; refletir sobre as condições do receptor talvez seja uma saída. 


\section{Referências}

BARTON, D. Literacy: an introduction to the ecology of written language. London: Blackwell, 1994.

BARTON, D.; HAMILTON, M. Local literacy: reading and writing in one community. London; New York: Routledge, 1998.

BRASIL. Ministério da Fazenda. Lei n. ${ }^{\circ}$ 6.404, de 15 de dezembro de 1976. Dispõe sobre as Sociedades por Ações. Diário Oficial da União, Brasília, DF, 17 dez. 1976. p. 1 (Suplemento). Disponível em: <http:// www.planalto.gov.br/ccivil_03/Leis/L6404consol.htm>. Acesso em: 21 ago. 2012.

BRAUDEL, F. Civilização material, economia e capitalismo, sécs. XV-XVIII. Tradução Telma Costa. São Paulo: Martins Fontes, 1996.

CARLINO, P. Escribir, leer y aprender en la universidad. Una introducción a la alfabetización académica. El Salvador; Buenos Aires: Fondo de Cultura Económica de Argentina, 2005.

ELIAS, N. O processo civilizatório. Rio de Janeiro: Jorge Zahar, 1994.

FISCHER, A. Letramento Acadêmico: uma perspectiva portuguesa. Acta Scientiarum: Language and Culture, Maringá, v. 30, n. 2, p. 177-187, jul./ dez. 2008.

FREIRE, P. Pedagogia do Oprimido. 12. ed. Rio de Janeiro: Paz e Terra, 1983.

GADOTTI, M.; TORRES, C. A. Educação popular: utopia latinoamericana. São Paulo: Cortez; EDUSP, 1994.

GEE, J. P. Social linguistics and literacies: ideology in Discourses. 2. ed. London; Philadelphia: The Farmer Press, 1996.

GOLDFARB, J. L. Voar é também com os homens: o pensamento de Mario Schenberg. São Paulo: EDUSP, 1994.

KLEIMAN, A. Oficina de leitura: teoria e prática. Campinas: Pontes, 1993. 
LEA, M. R.; STREET, B. Student writing in higher education: an academic literacies approach. Studies in Higher Education, London, v. 23, n. 2, p. 157-16, June 1998.

MACHADO, A. R.; LOUSADA, E.; ABREU-TARDELLI, L. S. Resenha. São Paulo: Parábola, 2004.

OLIVEIRA, E. F. Letramento Acadêmico: principais abordagens sobre a escrita dos alunos no ensino superior. In: ENCONTRO MEMORIAL DO ICHS, 2., 2009, Mariana. Anais... Mariana: ICHS, 2009. p. 1-10. Disponível em: <http://www.ichs.ufop.br/memorial/anais2.html>. Acesso em: 21 ago. 2011.

ORTEGA Y GASSET, J. Ensayos filosóficos: biologia y pedagogia. Obras Completas. 2. ed. Madrid: Alianza, 1993. t. II.

PORTER, M. Vantagem competitiva: criando e sustentando um desempenho superior. 11. ed. Rio de Janeiro: Campus, 1986.

RAMIRES, V. Gêneros textuais e relações de poder na comunidade acadêmica. Veredas, Juiz e Fora, v. 11, n. 1, p. 66-79, 2007. Disponível em: <http://www.ufff.br/revistaveredas/files/2009/12/artigo054.pdf>. Acesso em: 2 ago. 2012.

SOARES, M. B. Alfabetização e letramento: caminhos e descaminhos. Pátio, n. 29, fev. 2004. Disponível em: <http://pt.scribd.com/doc/ 18892732/Artigo-Alfabetizacao-e-Letramento-Magda-Soares1>. Acesso em: 21 ago. 2012.

STREET, B. V. Literacy in theory and practice. London: Cambridge University Press, 1984.

TERZI, S. B. A construção do curriculo nos cursos de letramento de jovens e adultos não escolarizados. 2006. Disponível em: <http://www.cereja.org.br/ arquivos_upload/sylviaterzi.pdf> Acesso em: 21 ago. 2012. 